\title{
The Medical and Surgical Treatment of Glaucoma
}

\author{
Thomas S. Dietlein, Manuel M. Hermann, Jens F. Jordan
}

\section{SUMMARY}

Background: Ongoing demographic changes in Europe are heightening the importance of adequate treatment for glaucoma, a disorder that is markedly more common in the elderly.

Method: A selective search for relevant literature, including Cochrane Reviews and the guidelines of the European Glaucoma Society, regarding the topical and surgical treatment of glaucoma.

Results: It is recommended that the intraocular pressure (IOP) should be lowered by $20 \%$ to $50 \%$ from its baseline value, depending on the extent of already existing damage, the rate of progression, the baseline IOP, and the age of the patient. Topical monotherapy can lower the IOP by $15 \%$ to $30 \%$. The success rate of filtration surgery has risen because of the intraoperative application of topical antimetabolites and currently ranges from $50 \%$ to $90 \%$, depending on the study.

Conclusions: The goal of glaucoma treatment is to protect the patient from blindness and visual impairment while keeping the treatment-related decline in quality of life to a minimum. Any type of glaucoma treatment, be it medical or surgical, must further this aim in consideration of the situation of the individual patient.

Key words: glaucoma, intraocular pressure, medical treatment, glaucoma surgery

Cite this as: Dtsch Arztebl Int 2009; 106(37): 597-606 DOL 10.3238/arztebl.2009.0597

Zentrum für Augenheilkunde der Universität Köln: Prof. Dr. med. Dietlein, Dr. med. Hermann

Universitäts-Augenklinik Freiburg i. Br.: PD Dr. med. Jordan
T he term "glaucoma" designates a pathophysiologically heterogeneous group of eye diseases whose common feature is that they result in a characteristic type of optic neuropathy if untreated. Glaucoma is one of the more common causes of blindness in industrialized countries.

According to the World Health Organization (WHO), 4.5 to 5 million people are blind around the world because of glaucoma (e1). In Germany alone, about 800000 to 900000 people suffer from glaucoma, and it is estimated that nearly the same number have undiagnosed glaucoma. Its prevalence rises with age, from ca. $2.4 \%$ in persons over 40 to more than $7 \%$ in persons over 75; there is no clear difference in prevalence between men and women (1, e2).

The learning aims of this article for the reader are

- to acquire knowledge of the diagnosis and treatment of glaucoma that is relevant to clinical practice, because this disease is becoming more common as a result of demographic shifts,

- to become acquainted with medical and surgical treatments that can lower the intraocular pressure, and to understand their indications.

The authors searched the PubMed database for "glaucoma" to identify important current review articles and large-scale clinical studies with high levels of evidence, then selected some of these to serve as the basis for this paper. The essential current guidelines for the treatment of glaucoma are those of the European Glaucoma Society and of the German Ophthalmological Society; both of these guidelines can be retrieved from the Internet (8, e5). Systematic reviews in the Cochrane database were also consulted.

In view of the large subject and the limited space available, a variety of further diagnostic aspects and therapeutic options could not be discussed in this article.

\section{Prevalence}

According to the World Health Organization (WHO), 4.5 to 5 million people are blind around the world because of glaucoma. 


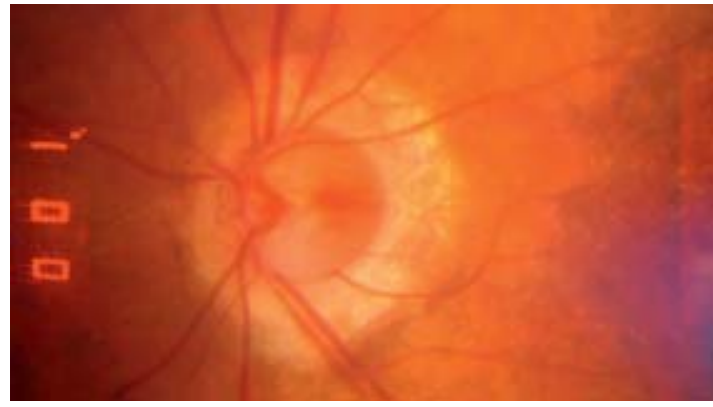

Figure 1: Glaucomatous papilla in a patient with myopia in an advanced stage, with a very large excavation (loss of neuroretinal tissue) and typical displacement of the vascular trunk in the nasa direction. A hemorrhage is visible at the edge of the papilla at 3 o'clock. The observed peripapillary lightening is mainly due to the pronounced myopia.

\section{Disease entities}

In Western Europe, open-angle glaucoma is much more common than narrow-angle glaucoma. Elevated intraocular pressure in open-angle glaucoma is usually due to pathologically elevated outflow resistance in the trabecular meshwork. This leads to high intraocular pressure, of which the patient is hardly ever aware and which usually leads, over the years, to glaucomatous optic neuropathy and to a progressive visual field defect. Elevated intraocular pressure $(>21 \mathrm{~mm} \mathrm{Hg})$ is the main risk factor for glaucoma; other risk factors include markedly fluctuating intraocular pressure, myopia, a family history of glaucoma, a thin cornea, and other associated ocular pathologies, such as the pseudoexfoliation syndrome $(1,2)$. Epidemiological studies have shown that the risk of glaucoma rises by $12 \%$ with every $1 \mathrm{~mm} \mathrm{Hg}$ rise in intraocular pressure (3).

In narrow-angle glaucoma, the peripheral chamber angle is typically narrow, in a relatively short, hyperopic, phakic eye. So-called pupillary block can drive the intraocular pressure to extremely high values ( $>50$ $\mathrm{mm} \mathrm{Hg}$ ) and produce a classic painful "glaucoma attack," with conjunctival hyperemia, corneal clouding, and an irregularly deformed pupil.

Normal-pressure glaucoma (by definition, a progressive change of the optic nerve that is typical of glaucoma, but with intraocular pressure values no higher than $21 \mathrm{~mm} \mathrm{Hg}$, which is considered normal) should probably not be considered a single disease entity, but rather a part of the broad spectrum of open-angle glaucoma in which many risk factors besides intraocular pressure are at work, including low blood pressure, vasospastic signs such as migraine, familial predisposition, low bodymass index, and a thin cornea (4-7, e3, e4).

Congenital glaucoma is rare ( 1 per 10000 births) and is characterized by increased corneal radii, (often) cloudy cornea, tearing, and photophobia.

Secondary glaucoma is also rare. It is seen in rare hereditary syndromes, such as aniridia, and in traumatic secondary glaucoma, aphakic glaucoma, steroid-induced glaucoma, and neovascular glaucoma of various causes, including central vein thrombosis and diabetes mellitus.

\section{Diagnostic aspects}

The basic diagnostic evaluation of glaucoma comprises intraocular pressure measurement (tonometry) and morphological and functional studies of the eye.

The intraocular pressure is generally measured with applanation tonometry, which was introduced by Goldmann in 1954/55. In this technique, the cornea is topically anesthetized, its apex is "flattened" with a measuring head, and the applied force necessary to deform it is taken as an index from which the intraocular pressure can be derived. Depending on the apparatus used, applanation tonometry can be performed with the patient supine or sitting. The measured value depends not only on the examiner, but also on the biomechanical properties of the cornea, including its thickness. The newer tonometric techniques include rebound tonometry, which does not require anesthesia of the cornea, and dynamic contour tonometry, which is more cumbersome but less susceptible to inaccuracy resulting from the properties of the cornea. Goldmann applanation tonometry is still considered the standard technique.

The different types of glaucoma are characterized by a similar pathology of the optic nerve head, whose severity depends on the stage of the disease. The main pathological findings are

- neuroretinal rim loss

- increased excavation of the papilla,

- nasal displacement of the vessels of the papilla (Figure 1),

- "bayoneting" (sharp bending) of the vessels, and

- hemorrhages at the periphery of the papilla.

Loss of the neuroretinal rim reflects a loss of retinal ganglion cells.

A visual field defect is usually not seen on perimetric examination until the morphologically evident tissue

\section{Risk factors}

- Elevated intraocular pressure (>21 mm Hg)

- Marked fluctuations of intraocular pressure

- Myopia

- Family history of glaucoma

- Thin cornea

- Other associated pathology of the eye

\section{Basic diagnostic evaluation}

- Measurement of intraocular pressure (tonometry)

- Morphological and functional studies of the eye 
damage at the neuroretinal rim is markedly advanced $(>40 \%)$. When the papilla is damaged, but the visual field is found to be normal, the patient is said to have "preperimetric glaucoma," and follow-up examinations focus on the optic disk findings (e6).

\section{Pharmacotherapy}

Multiple large-scale randomized studies have shown, at a high level of evidence, that local treatment-either medical or surgical-lowers the intraocular pressure and protects the visual field to a statistically significant extent in primary chronic open-angle glaucoma, normalpressure glaucoma, and ocular hypertension (1, 4-7, 9 $10, \mathrm{e} 7)$. In contrast, the available evidence does not suffice to determine which medical treatment or surgical procedure should be used as the first choice, or under what circumstances a patient who has been treated medically should undergo surgery.

In the stepwise treatment algorithm recommended by the European Glaucoma Society (EGS), pharmacological reduction of the intraocular pressure is the first step, followed by laser surgery of the trabecular meshwork and (filtering) glaucoma surgery.

The EGS recommends that the therapeutic target for the intraocular pressure should be set as a function of the pre-existing degree of optic nerve damage, the patient's life expectancy, the rapidity of progression, and the baseline value of the intraocular pressure before treatment (8).

Generally speaking, a drastic reduction of the intraocular pressure by $30 \%$ to $50 \%$ is more likely to be needed in a later than in an earlier stage of the disease.

There are two approaches to the medical reduction of intraocular pressure:

- Reducing the production of aqueous humor production, with the use of:

- beta-blockers (inhibition of the beta-mediated stimulation of $\mathrm{Na}^{+} / \mathrm{K}^{+}$-ATPase)

- carbonic anhydrase inhibitors

- sympathomimetic drugs (activation of the alphamediated inhibition of $\mathrm{Na}^{+} / \mathrm{K}^{+}$-ATPase)

- Increasing the outflow aqueous humor, with the use of:

- cholinergic/parasympathomimetic drugs and prostaglandin derivatives (trabecular meshwork)

- sympathomimetic drugs (uveoscleral outflow)

- prostaglandin derivatives (uveoscleral outflow)

The advantages of improving aqueous humor outflow are the following:
- correction of the outflow deficit that is the primary cause of elevated intraocular pressure

- improved protection against fluctuations and dangerous spikes of the intraocular pressure

- maintenance of the physiological production of the aqueous humor and preservation of its normal functions (e.g., nutrition of the lens and cornea, removal of metabolic waste products).

According to the EGS guidelines, prostaglandin analogs, beta-blockers, alpha-2 agonists, and topical carbonic anhydrase inhibitors are the agents of first choice (8).

\section{Topical prostaglandin analogs}

Prostaglandin analogs (PGA) are among the more effective medications for reducing the intraocular pressure, with a lowering effect of as much as $33 \%$ (11). Their failure rate, defined as a less than $20 \%$ reduction, is $15 \%$ to $20 \%$ (e8).

Topical PGA have the following advantages over topical beta-blockers:

- application only once a day, usually in the evening (compliance)

- pressure reduction through improved outflow (uveoscleral and trabecular)

- prolonged pressure-lowering effect, lasting up to 48 hours

- a very short systemic half-life, and therefore a very low rate of systemic side effects.

Up to $50 \%$ of patients develop irreversible iridial hyperpigmentation (12), and patients should also be warned of the risk of increased eyelash growth. The risk of cystoid macular edema (water deposition in the middle of the retina, impairing central visual acuity) due to PGA treatment is of uncertain magnitude as far as can be determined from current data. If macular edema develops under PGA treatment, an attempt should be made to discontinue the treatment. In the authors' personal experience, however, the risk of macular edema is not so high that PGA would need to be discontinued before intraocular surgery. A recently published retrospective study supports our opinion (e9).

After application, PGA are split by corneal esterases to generate the active form of the drug. Latanoprost and travoprost have roughly equivalent pressure-lowering activity. Tafluprost has recently become available in a preservative-free formulation.

Bimatoprost belongs to the prostamide subclass; its pressure-lowering potential resembles that of latanoprost or travoprost.

\section{Pharmacotherapy}

Which medications and surgical procedures are the treatments of first choice, and under what circumstances a patient who has been under medical treatment should undergo surgery, are questions to which the literature does not yet provide any securely evidence-based answers.

\section{Topical prostaglandin analogs}

Prostaglandin analogs lower the intraocular pressure by as much as $33 \%$ and are thus among the more effective medications for this purpose.

The failure rate is $15 \%$ to $20 \%$. 
Combined preparations (PGA and beta-blockers) are applied once in the morning, so that the topically applied beta-blocker can exert a more powerful effect on aqueous humor production, which is at its highest in the morning hours.

\section{Topical beta-blockers}

The average net pressure reduction from topical betablockers is $20 \%$ to $25 \%$ of the baseline value (11). Substances in this class that are currently in use include timolol, betaxolol, carteolol, levobunolol, and metipranolol.

Contraindications to the use of topical beta-blockers include sinus bradycardia, grade II/III atrioventricular block, congestive heart failure, bronchial asthma, and chronic obstructive pulmonary disease (COPD). As most of the pharmacologically active drug is resorbed through the nasal mucosa, the tear duct should be manually compressed after the eye drop is instilled in order to minimize systemic resorption.

Topical beta-blocker treatment often causes a problematic local worsening of sicca symptoms. The indication for topical beta-blockers in small children should be considered carefully, as it also should in pregnant women and nursing mothers in particular, because the active drug can accumulate in breast milk.

\section{Topical alpha-agonists}

Alpha-agonists lower the intraocular pressure both by reducing aqueous humor production and by increasing the uveoscleral outflow. Alpha-2 agonists are contraindicated in children up to age 8 because of their potential central sedating effect. This class of drugs includes clonidine, apraclonidine, and brimonidine.

Brimonidine can lower the intraocular pressure by as much as $27 \%$ (11). As it is alpha-2 selective, it has almost no mydriatic effect and no more than a mild vasoconstrictive effect. It does, however, have a high rate of local allergic reactions (over 25\%).

Clonidine $0.125 \%$, a more lipophilic agent, enters the central nervous system more easily and has a higher rate of systemic side effects. It also accumulates in breast milk and should therefore not be given to pregnant women or nursing mothers. It has the advantage of being available without preservatives. Apraclonidine $0.5 \%-1.0 \%$ and nonselective adrenergic drugs such as dipivefrine $0.1 \%$ are currently considered second-line medications because of their systemic and local side effects.

\section{Topical beta-blockers}

The average net reduction of intraocular pressure with topical beta-blockers is $20 \%$ to $25 \%$ of the baseline value. Substances in this class that are currently in use include timolol, betaxolol, carteolol, levobunolol, and metipranolol.

\section{Topical parasympathomimetic (miotic) agents}

Pilocarpine has been known since 1870 to lower the intraocular pressure; it is available in concentrations ranging from $0.5 \%$ to $6 \%$. It lowers the intraocular pressure by about $20 \%$. Miotic agents are now hardly ever given for indications other than narrow-angle glaucoma or the plateau-iris syndrome, in which they serve to keep the trabecular meshwork open. They are used to immobilize the iris in pigment-dispersion glaucoma and pseudoexfoliation glaucoma, thereby lowering the extent of pigment release and pseudoexfoliation, respectively, while also improving aqueous humor outflow through the trabecular meshwork. The induced miosis can, however, cause painful spasms of the ciliary body. Moreover, contraction of the ciliary muscle can induce up to -8 diopters of myopia. Miosis can also lead to marked visual impairment, particularly in dim light and in the presence of a cataract. Miotic agents are available in combined preparations, mostly together with beta-blockers.

\section{Topical and systemic carbonic anhydrase inhibitors}

Topical carbonic anhydrase inhibitors (CAI) for the treatment of glaucoma and ocular hypertension $(\mathrm{OHT})$ include brinzolamide and dorzolamide, which produce a $20 \%$ to $25 \%$ net lowering of the intraocular pressure (11). Topical CAI lower aqueous humor production by inhibiting the enzyme carbonic anhydrase in the ciliary body epithelium. They are available in fixed combinations with beta-blockers, as well as in preservative-free formulations.

The carbonic anhydrase inhibitor acetazolamide can be given systemically either by mouth or intravenously, the latter only in cases of acutely elevated intraocular pressure. Acetazolamide in doses up to $1000 \mathrm{mg}$ po qd is usually given when topical medications are not tolerated (or no longer tolerated), as a temporizing measure before glaucoma surgery. The dosage and duration of treatment are limited by the drug's side effects: electrolyte disturbances (potassium replacement), paresthesiae, confusion, fatigue, kidney stones, circulatory disturbances, nausea, diarrhea, and a bitter taste. Topical and systemic carbonic anhydrase inhibitors should not be given to patients who are allergic to sulfonamides.

Topical carbonic anhydrase inhibitors have no additional effect when given in combination with systemic carbonic inhibitors. Simultaneous topical and systemic administration is, therefore, not recommended.

\section{Topical alpha-agonists}

Alpha-agonists lower the intraocular pressure by slowing the production of aqueous humor and increasing uveoscleral outflow. Alpha-2 agonists are contraindicated in children up to the age of 8 years because of their potential central sedating side effects. 


\section{Hyperosmotic agents}

The intravenous administration of a hyperosmotic drug (mannitol) is reserved for short-term emergency treatment, e.g., in an acute glaucoma attack with extremely high intraocular pressure.

\section{Treatment other than by lowering the intraocular pressure}

Many types of treatment for glaucoma that do not lower the intraocular pressure are currently under discussion, for potential use particularly in patients with normalpressure glaucoma. The studies performed to date, however, have not yielded any high-level evidence supporting their use (e7). Proposed treatments in this class include the administration of low doses of calcium antagonists (nimodipine, nifedipine) to patients with vasospastic manifestations (e10), and of low doses of mineralocorticosteroids (fludrocortisone) to patients with marked arterial hypotension (e11). Neuroprotective agents, e.g., glutamate-receptor antagonists, have not yet been shown effective against glaucoma. Nor is there sufficient evidence to support the use of acupuncture for glaucoma (e12).

\section{Surgical treatments for the lowering of intraocular pressure Indications}

If glaucomatous optic neuropathy or visual field defects (Figure 2) progress in a patient with chronic open-angle glaucoma despite the administration of two or three topical treatments, it is generally time to consider surgical intervention (e13). The same holds if local therapy is urgently needed but is not tolerated because of systemic or local side effects, or if the regular use of eye drops is an unrealistic prospect in view of the patient's social situation or comorbid conditions. For very old patients (aged 85 and above), the indications for surgery should be weighed carefully on an individual basis, as it can take years or even decades, depending on the intraocular pressure values, for any functional deficits to develop that will impair the patient's everyday activities.

\section{Trabeculectomy with mitomycin C}

Trabeculectomy with mitomycin $\mathrm{C}$ is the surgical treatment of first choice for medically intractable glaucoma. In a large-scale randomized trial, the intraocular pressure was significantly lower, after two to nine years of postoperative follow-up, than in the medically treated control group (15 vs. $17.2 \mathrm{~mm} \mathrm{Hg}$ ) (13). Depending on the trial

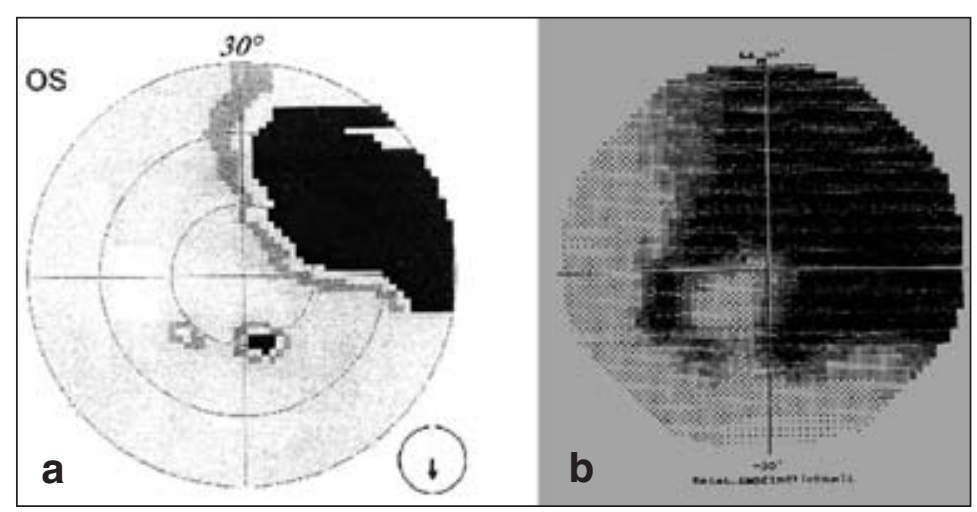

Figure 2: The course of a visual field defect (demonstrated with two different perimetric apparatuses) in a patient with chronic open-angle glaucoma and intermittent intraocular pressure spikes of up to $35 \mathrm{~mm} \mathrm{Hg}$. (a) The defect (black) is limited to one quadrant at first, but widens out (b) over time to give the typical appearance of a "glaucoma field defect."

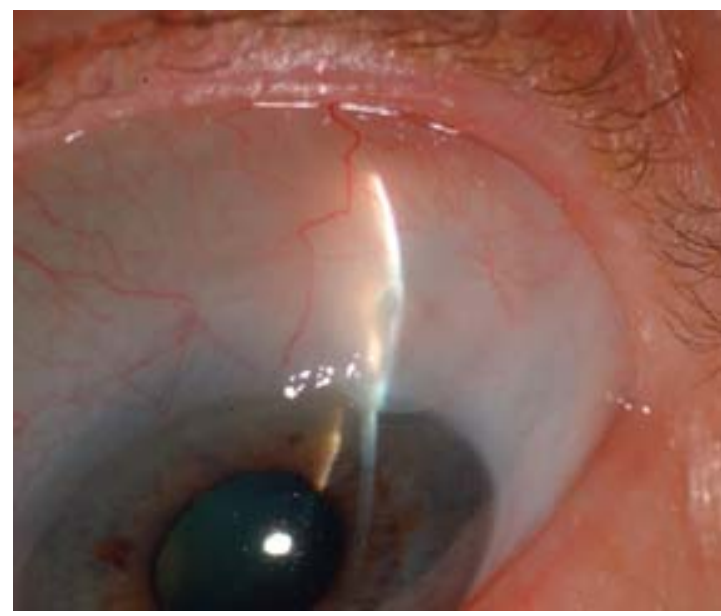

Figure 3:

The filtering bleb after trabeculectomy with mitomycin C. The conjunctiva bulges markedly at the limbus. This procedure enables the aqueous humor to enter the subconjunctival space. and the patient's individual situation, the procedure's success rate (variously defined) after one to five years lies between $50 \%$ and 90\% (14-16). "Success" typically means that the visual field defect remains stable and the intraocular pressure does not rise above $20 \mathrm{~mm} \mathrm{Hg}$.

The goal of the procedure is to establish a permanent transscleral outflow of aqueous humor from the eye into the subconjunctival space. Thus, in the ideal case, a mild bulging of the filtering bleb is seen in the upper quadrant of the globe (Figure 3). Cataract acceleration is a side

\section{Topical and systemic carbonic anhydrase inhibitors \\ Topical and systemic carbonic anhydrase inhibitors should not be given to patients who are allergic to sulfonamides.}

\author{
Proposed treatments for glaucoma that do \\ not lower the intraocular pressure \\ Neuroprotective agents, e.g., glutamate-receptor \\ antagonists, have not yet been shown effective \\ against glaucoma. Nor are there adequate data to \\ support the use of acupuncture in glaucoma.
}




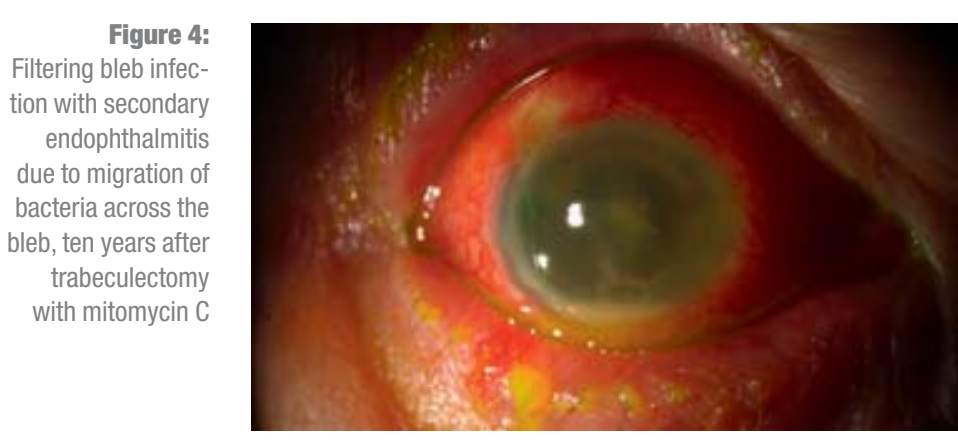

Figure 5: Silicon catheter in the anterior chamber of the eye after implantation of a glaucoma implant in the nasal lower quadrant of the globe

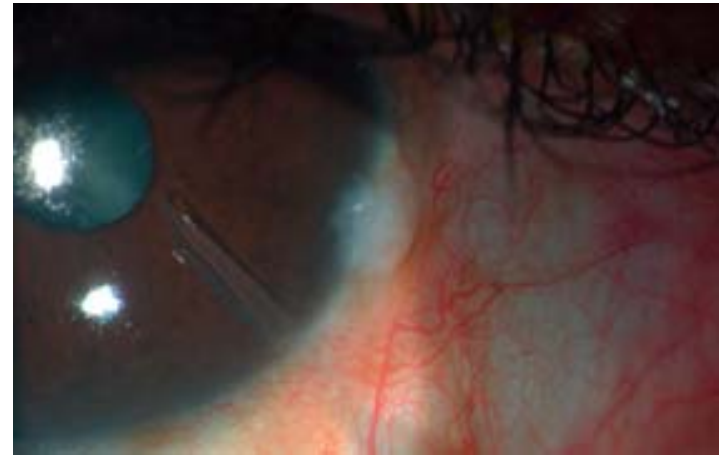

effect of the procedure, because aqueous humor no longer bathes the lens. As a large portion of the filtering bleb can be scarred by wound healing, trabeculectomy is now usually combined with the intraoperative local application of mitomycin $\mathrm{C}$ to inhibit fibroblast activity (e14). In patients at special risk, this is sometimes supplemented with the postoperative, subconjunctival administration of 5-fluorouracil (e15). The procedure is performed under general anesthesia in children and adolescents, but adults and older patients can have it under local, preferably subconjunctival anesthesia.

Unlike modern, "bloodless" cataract surgery, however, this procedure requires a temporary interrruption or discontinuation of any anticoagulants the patient may be taking, as heavy bleeding worsens the functional result of this type of filtration surgery.

Regular postoperative follow-up is needed even when the procedure initially meets with success: after the application of mitomycin $\mathrm{C}$, the filtering bleb can develop microlesions, even years later, through which bacteria can enter the bleb, migrate across it, and cause secondary endophthalmitis (Figure 4) $(17,18)$. The risk of bacterial blebitis or endophthalmitis after glaucoma surgery is $1 \%$ to $1.5 \%$ per patient-year $(19,20)$. Endophthalmitis can also be a complication of implants for glaucoma; this occurs up to five times more frequently in children (21).

\section{Implants for glaucoma}

Glaucoma implant surgery is being increasingly used around the world as a method of last resort after failed trabeculectomy. In these procedures, the aqueous humor is shunted out of the anterior chamber (Figure 5) through a thin silicon tube (inner diameter, $300 \mu \mathrm{m}$ ) to an episcleral footplate located behind the equator of the globe. No clinical trials have yet shown any type of implant to be better than any other with a high level of evidence (e16). Many patients treated with glaucoma implants still need local treatment for glaucoma thereafter (16). While precise figures are unavailable, glaucoma implants certainly account for no more than a small percentage $(<2 \%)$ of the operations now being performed for open-angle glaucoma in Germany, with filtration surgery making up the rest. The percentage is higher for intractable types of glaucoma. The largest clinical trial comparing glaucoma implants with filtration surgery as the current standard treatment has shown comparably good results from both treatments with respect to success rates at 1 year (ca. 90\%), intraocular pressure (ca. $12 \mathrm{~mm} \mathrm{Hg}$ ), and safety, although the implant group received more medications postoperatively (the "Tube Versus Trabeculectomy" [TVT] study). A long-term observational study of a large collective of insured patients revealed, however, that difficult problems such as corneal opacification can arise years after implant surgery, and then in every fourth patient (20).

\section{Trabeculotomy/goniotomy}

Trabeculotomy and goniotomy are the usual surgical treatments of congenital glaucoma (22). The trabecular meshwork is surgically opened either from within (goniotomy) or from without (trabeculotomy) to create a direct communication between the anterior chamber of the eye and Schlemm's canal. Trabeculectomy is also sometimes performed as the primary surgical treatment of congenital glaucoma and seems to be comparably effective (23). For congenital glaucoma, in distinction to other types of glaucoma, surgery is generally the best primary treatment.

\section{Surgical treatment to lower the intraocular pressure}

If glaucomatous optic neuropathy or visual field defects should progress in a patient with chronic open-angle glaucoma despite the administration of two or three topical treatments, it is generally time to consider surgical intervention.

\section{Trabeculectomy with mitomycin C}

Trabeculectomy with mitomycin $\mathrm{C}$ is the method of first choice for the surgical treatment of medically intractable glaucoma. 


\section{Laser techniques Laser cyclophotocoagulation}

Unlike the other techniques discussed above, whose purpose is to lower the intraocular pressure by increasing the outflow of aqueous humor from the anterior chamber, cyclophotocoagulation is intended rather to decrease its inflow by destroying the non-pigmented epithelial cells of the ciliary body that produce it. The ciliary body is coagulated with a laser, either from inside the eye under endoscopic visualization, or else through the sclera without opening the globe. No clear doseeffect relationship has been shown (e17), and overtreatment carries the risk of phthisis bulbi (shrinking of the globe); thus, the treatment is usually applied in underdosed and fractionated fashion, and a single application only rarely brings long-term success. There is wide disagreement among surgical ophthalmologists as to the value of this treatment: both its effectiveness and its underlying principle have been called into question (e17, e18).

\section{Laser trabeculoplasty}

Selective laser trabeculoplasty with a double-frequency neodymium:YAG laser is about as effective as argon laser trabeculoplasty but applies far less energy overall and therefore has less severe side effects. Laser trabeculoplasty reduces the intraocular pressure by no more than 5-6 mm Hg, a much smaller amount than filtration surgery (e19). Therefore, it is typically used in patients whose glaucoma is not yet very advanced and who cannot tolerate locally applied medications, patients whose intraocular pressure is no higher than $25 \mathrm{~mm} \mathrm{Hg}$ at the outset, or patients who decline intraocular surgery, e.g., persons of very advanced age.

Selective laser trabeculoplasty yields a $20 \%$ reduction in intraocular pressure for one year in $60 \%$ to $80 \%$ of the eyes treated $(24$, e20), though some published success rates are markedly lower (e21).

\section{New surgical methods}

New surgical methods have been developed recently at a number of centers; their value is currently uncertain, as randomized comparisons with standard treatment are lacking. One of these methods is viscocanaloplasty, in which, after $360^{\circ}$ viscodilatation of Schlemm's canal, a loop of nonresorbable Prolene suture is placed in it and knotted under light tension (e22).

Another method, deep sclerectomy with or without resorbable implants, is related to trabeculectomy, differ- ing from it in that a deep scleral flap is excised, but the trabecular meshwork is not completely opened. As the anterior chamber of the eye remains primarily unopened, this operation produces less postoperative irritation within the eye, but it may not reduce the intraocular pressure quite as effectively as trabeculectomy with mitomycin C (e23).

\section{Surgery for narrow-angle glaucoma}

The oldest surgical treatment of glaucoma is iridectomy, which was introduced by Albrecht von Graefe in the 19th century and is now mainly performed as laser iridotomy with a neodymium:YAG laser. It is the treatment of choice for the prevention of pupillary block in narrow-angle glaucoma (25).

Pupillary block can also arise in uveitis because of circumferential adhesion of the pupil to the anterior surface of the lens (posterior synechia), resulting in a massive rise of the intraocular pressure. Iridectomy is needed in this situation but should be performed surgically, as the smaller opening produced by laser iridotomy will close again in more than half of all cases.

\section{The prognosis after glaucoma surgery}

The risk of blindness in the first 12 months after glaucoma surgery is very low, especially in comparison to the natural history of untreated glaucoma; after primary trabeculectomy, this risk is approximately $0.4 \%$ (20). Blindness is caused by postoperative endophthalmitis or by a postoperative intra- or subchoroidal hemorrhage. Hemorrhage is most likely to occur when the intraocular pressure has been extremely high (above $50 \mathrm{~mm} \mathrm{Hg}$ ) for a long time and is suddenly reduced by surgery to less than $4 \mathrm{~mm} \mathrm{Hg}$.

Though blindness is rare, a postoperative loss of central visual acuity is more common, occurring at a frequency of $20 \%$ to $30 \%$ (16). Its various causes range from cataract, macular edema, and retinal wrinkling (Figure 6) to a late-onset visual field defect that may arise months after surgery, but is still due to the high intraocular pressure present preoperatively.

Patients rightly associate the diagnosis of glaucoma with a lifelong need for treatment and with the possibility of blindness in the future. They therefore need not just ophthalmological care in the narrow sense of medical problem-solving, but also individualized psychological guidance. This is particularly so because, in the first year of treatment, well over half of all patients have problems

\section{Implants for glaucoma}

No clinical trials have yet shown any type of implant to be better than any other with a high level of evidence.

\section{Congenital glaucoma}

Trabeculotomy and goniotomy are the usual surgical treatments of congenital glaucoma. 


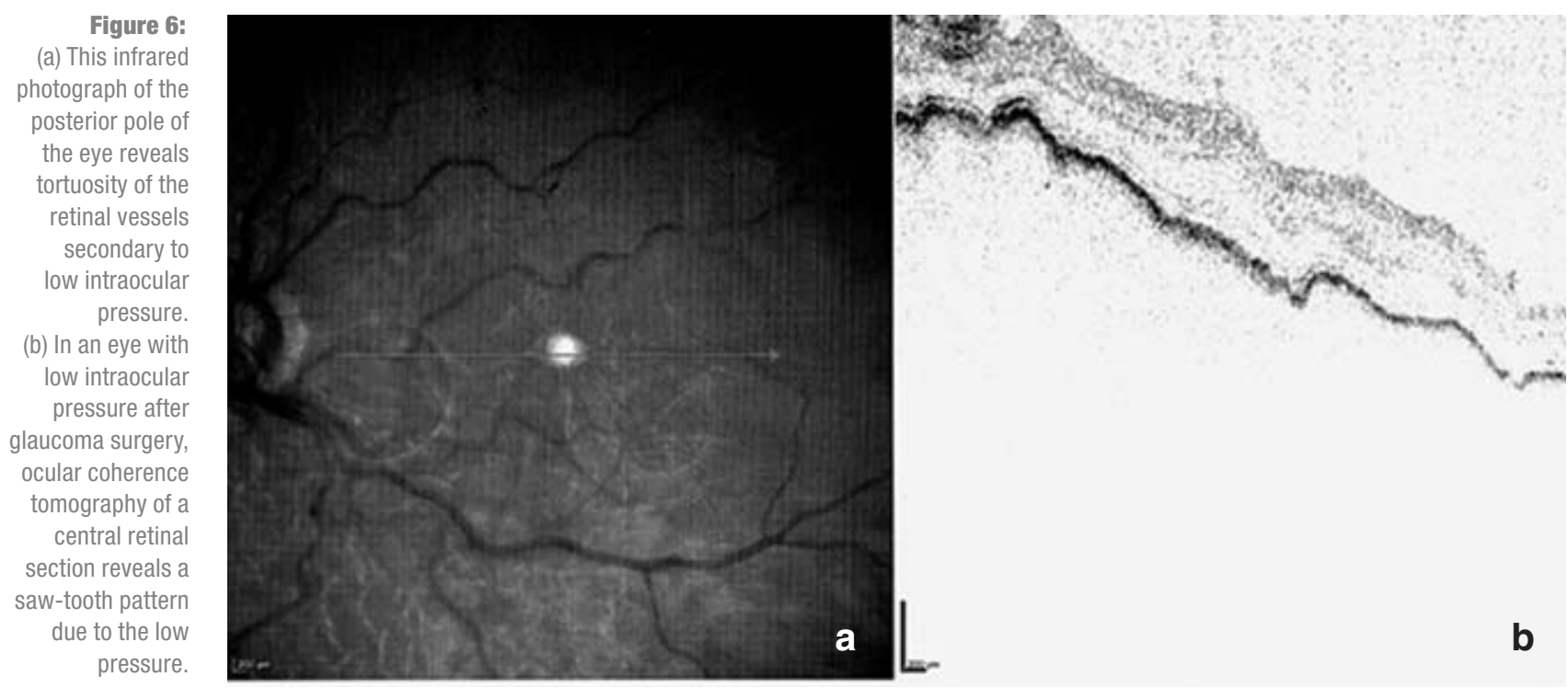

complying with their prescribed antiglaucomatous medication (e24).

\section{Conflict of interest statement}

Professor Dietlein has received lecture honoraria from Chibret/MSD, Alcon Pharma, Pfizer, and Ellex. Dr. Hermann was enabled to attend the Glaucoma Congress in Munich in April 2009 as well as a Glaucoma Conference in Geneva in January 2008 by the financial sponsorship of MSD, Sharp \& Dohme GmbH. PD Dr. Jordan has received financial support from Alcon Pharma and Pfizer.

Manuscript received on 6 May 2009; revised version accepted on 13 August 2009.

Translated from the original German by Ethan Taub, M.D.

\section{REFERENCES}

1. Heijl A, Leske MC, Bengtsson B, Hyman L, Bengtsson B, Hussein M: Reduction of intraocular pressure and glaucoma progression: results from the Early Manifest Glaucoma Trial. Arch Ophthalmol 2002; 120: 1268-79.

2. Brandt JD, Beiser JA, Kass MA, Gordon MO: Central corneal thickness in the Ocular Hypertension Treatment Study (OHTS). Ophthalmology 2001; 108: 1779-88.

3. Nemesure B, Honkanen R, Hennis A, Wu SY, Leske MC, Barbados Eye Studies Group: Incident open-angle glaucoma and intraocular pressure. Ophthalmology 2007; 114: 1810-5.

4. Collaborative Normal-Tension Glaucoma Study Group: Comparison of glaucomatous progression between untreated patients with normaltension glaucoma and patients with therapeutically reduced intraocular pressures. Am J Ophthalmol 1998; 126: 487-97.

5. The Advanced Glaucoma Intervention Study (AGIS): 7. The relationship between control of intraocular pressure and visual field deterioration.The AGIS Investigators. 2000; Am J Ophthalmol 130: 429-40.
6. Collaborative Normal-Tension Glaucoma Study Group: Natural history of normal-tension glaucoma. Ophthalmology 2001; 108: 247-53.

7. Collaborative Normal-Tension Glaucoma Study Group: The effectiveness of intraocular pressure reduction in the treatment of normaltension glaucoma. Am J Ophthalmol 1998; 126: 498-505.

8. European Glaucoma Society: Terminologie und Handlungsrichtlinien für die Glaukome. 3.rd ed. (2008), DOGMA, Savona, Italien (www.eugs.org)

9. Leske MC, Heijl A, Hussein M, Bengtsson B, Hyman L, Komaroff E: Factors for glaucoma progression and the effect of treatment: the early manifest glaucoma trial. Arch Ophthalmol 2003; 121: 48-56.

10. Lichter PR, Musch DC, Gillespie BW, Guire KE, Janz NK, Wren PA, Mills RP; CIGTS Study Group: Interim clinical outcomes in the Collaborative Initial Glaucoma Treatment Study comparing initial treatment randomized to medications or surgery. Ophthalmology 2001; 108: 1943-53.

11. van der Valk R, Webers CA, Schouten JS, Zeegers MP, Hendrikse F, Prins MH: Intraocular pressure-lowering effects of all commonly used glaucoma drugs: a meta-analysis of randomized clinical trials. Ophthalmology 2005; 112: 1177-85.

12. Pfeiffer N, Grierson I, Goldsmith H, Appleton P, Hochgesand D, Winkgen $A$ : Fine structural evaluation of the iris after unilateral treatment with latanoprost in patients undergoing bilateral trabeculectomy (the Mainz II study). Arch Ophthalmol 2003; 121: 23-31.

13. Musch DC, Gillespie BW, Niziol LM, Cashwell LF, Lichter PR: Factors associated with intraocular pressure before and during 9 years of treatment in the collaborative initial glaucoma treatment study. Ophthalmology 2008; 115: 927-33.

14. Alwitry A, Patel V, King AW: Fornix vs. limbal based trabeculectomy with mitomycin C. Eye 2005; 19: 631-5.

\section{New surgical techniques}

In recent years, new surgical techniques have been developed at a number of surgical centers. Their clinical utility is still uncertain, as there are as yet no data from randomized studies comparing them to the standard procedures.

\section{The prognosis after glaucoma surgery}

The risk of blindness in the first 12 months after glaucoma surgery is very low, especially in comparison to the natural history of untreated glaucoma. 
15. Casson R, Rahman R, Salmon JF: Long term results and complications of trabeculectomy augmented with low dose mitomycin $\mathrm{C}$ in patients at risk for filtration failure. $\mathrm{Br} \mathrm{J}$ Ophthalmol 2001; 85: 686-8.

16. Gedde SJ, Schiffman JC, Feuer WJ, Herndon LW, Brandt JD, Budenz $\mathrm{DL}$ : Treatment outcomes in the tube versus trabeculectomy study after one year of follow-up. Am J Ophthalmol 2007; 143: 9-22.

17. Solomon A, Ticho U, Frucht-Perry J: Late-onset, bleb-associated endophthalmitis following glaucoma filtering surgery with or without antifibrotic agents. J Ocul Pharmacol Ther 1999; 15: 283-93.

18. DeBry PW, Perkins TW, Heatley G, Kaufman P, Brumback LC: Incidence of late-onset bleb-related complications following trabeculectomy with mitomycin. Arch Ophthalmol 2002; 120: 297-300.

19. Greenfield DS, Suner IJ, Miller MP, Kangas TA, Palmberg PF, Flynn HW Jr: Endophthalmitis after filtering surgery with mitomycin C. Arch Ophthalmol 1996; 114: 943-9.

20. Stein JD, Ruiz Jr D, Belsky D, Lee PP, Sloan FA: Longitudinal rates of postoperative adverse outcomes after glaucoma surgery among medicare beneficiaries 1994 to 2005. Ophthalmology 2008; 115: 1109-16

21. Al-TorbakAA, Al-Shahwan S, Al-Jadaan I, Al-Hommadi A, Edward DP: Endophthalmitis associated with the Ahmed glaucoma valve implant. Br J Ophthalmol 2005; 89: 454-8.

22. Grehn F: The value of trabeculotomy in glaucoma surgery. Curr Opin Ophthalmol 1995; 6: 52-66.

23. Dietlein TS, Jacobi PC, Krieglstein GK: Prognosis of primary ab externo surgery for primary congenital glaucoma. Br J Ophthalmol 1999; 83: 317-22.

24. Nagar M, Ogunyomade A, O'Brart DPS, Howes F, Marshall J: A randomized, prospective study comparing selective laser trabeculoplasty with latanoprost for the control of intraocular pressure in ocular hypertension and open-angle glaucoma. Br J Ophthalmol 2005; 89: 1413-7.

25. Congdon NG, Friedman DS: Angle-closure glaucoma: impact, etiology, diagnosis, and treatment. Curr Opin Ophthalmol 2003; 14: 70-3.
Corresponding author

Prof. Dr. med. Thomas S. Dietlein

Zentrum für Augenheilkunde

Universität zu Köln

Kerpener Str. 62

50937 Köln, Germany

Thomas.Dietlein@uk-koeln.de

For e-references please refer to: www.aerzteblatt-international.de/ref3709

\section{Further Information on CME}

This article has been certified by the North Rhine Academy for Postgraduate and Continuing Medical Education.

Deutsches Ärzteblatt provides certified continuing medical education (CME) in accordance with the requirements of the Chambers of Physicians of the German federal states (Länder). CME points of the Chambers of Physicians can be acquired only through the Internet by the use of the German version of the CME questionnaire within 6 weeks of publication of the article, i.e., by 23 October 2009. See the following website: cme.aerzteblatt.de

Participants in the CME program can manage their CME points with their 15-digit "uniform CME number" (einheitliche Fortbildungsnummer, EFN). The EFN must be entered in the appropriate field in the cme.aerzteblatt.de website under "meine Daten" ("my data"), or upon registration. The EFN appears on each participant's CME certificate.

The solutions to the following questions will be published in volume 45/2009. The CME unit "Acute Infectious Diarrhea in Children" (issue 33/2009) can be accessed until 25 September 2009

For issue 41/2009 we plan to offer the topic "Perspectives on the Pathophysiology and Treatment of Sudden Hearing Loss"

\section{Solutions to the CME questionnaire in volume 28-29/2009:}

Westphal et al.: Infective Endocarditis—Prophylaxis, Diagnostic Criteria, and Treatment

Solutions: 1b, 2d, 3b, 4a, 5c, 6a, 7d, 8c, 9a, 10e 
Question 1

Which of the following is a typical symptom or sign of a glaucoma attack, i.e., an episode of acute pupillary block, in a patient with narrow-angle glaucoma?
a) Low body-mass index
b) Evidence of vasospasm
c) Oculomotor disturbance with diplopia
d) Corneal opacification
e) Arterial hypertension

Question 2

Which of the following is a typical sign of congenital glaucoma in a 2-month-old baby?
a) White pupillary reflex (leucocoria)
b) Vertical strabismus
c) Increased corneal radii
d) Epicanthus
e) Micropapilla

\section{Question 3}

What constellation of risk factors is typically observed in normal-pressure glaucoma?
a) Arterial hypertension, high BMI, marked farsightedness
b) Elevated intraocular pressure, marked farsightedness, nystagmus
c) Short eye, thick cornea, high BMI
d) Arterial hypertension, type 2 diabetes, thick cornea
e) Migraine, low blood pressure, thin cornea

\section{Question 4}

Which of the following is a typical change of the optic nerve head in glaucoma?
a) Temporal displacement of the vascular trunk
b) Hemorrhages at the periphery of the papilla
c) Hyperemia of the papilla
d) A thickened neuroretinal rim
e) Prepapillary vitreous opacification

\section{Question 5}

Which of the following can affect the measured values in applanation tonometry?
a) The biomechanical properties of the cornea
b) The size of the iris
c) The width of the pupil
d) The magnitude of the anisometry
e) The age of the patient

Question 6

What topical medication for lowering the intraocular pressure is contraindicated in children because of its adverse effects on the central nervous system?
a) Tafluprost
b) Brimonidine
c) Dorzolamide
d) Pilocarpine
e) Brinzolamide

Question 7

What class of topical anti-glaucoma drugs is contraindicated in patients that are allergic to sulfonamides?
a) Prostaglandins
b) beta-blockers
c) Miotic agents
d) alpha-agonists
e) Carbonic anhydrase inhibitors

Question 8

In which type of glaucoma is surgical treatment generally indicated as a primary measure, without a previous attempt to control the intraocular pressure with medications?
a) Pigment-dispersion glaucoma
b) Pseudoexfoliation glaucoma
c) Traumatic secondary glaucoma
d) Primary congenital glaucoma
e) Primary open-angle glaucoma

\section{Question 9}

For what disease is surgical iridectomy or laser iridotomy the treatment of choice?
a) Primary congenital glaucoma
b) Primary open-angle glaucoma
c) Pseudoexfoliation glaucoma
d) Narrow-angle glaucoma
e) Traumatic secondary glaucoma

\section{Question 10}

What are typical postoperative complications after trabeculectomy with mitomycin C?
a) Cataract, scarring of the filtering bleb, and blebitis
b) Retinal foramen, retinal detachment, and macular edema
c) Secondary vertical strabismus, head tilt, and diplopia
d) Photophobia, epiphora, and lacrimal duct stenosis
e) Eyelash growth, periocular discoloration, and change of iris color 


\title{
CONTINUING MEDICAL EDUCATION
}

\section{The Medical and Surgical Treatment of Glaucoma}

\author{
Thomas S. Dietlein, Manuel M. Hermann, Jens F. Jordan
}

\section{E-REFERENCES}

e1. World Health Organization: Prevention of Blindness and Visual Impairment. http://www.who.int/blindness/causes/priority/en/index7.html

e2. Michelson G: Epidemiologie, Screening, Ökonomie. In: Krieglstein GK (ed.): Glaukom 2006. Eine Konsensus-Konferenz, Springer-Verlag, Heidelberg 2007.

e3. Tokunaga T, Kashiwagi K, Tsumura T, Taguchi K, Tsukahara S: Association between nocturnal blood pressure reduction and progression of visual field defect in patients with primary open-angle glaucoma and normal-tension glaucoma. Jpn J Ophthalmol 2004; 48: 380-5.

e4. Dietlein TS: Normaldruckglaukom - ein praxisorientierter Überblick. Klin Monatsbl Augenheilkd 2009; 226: R75-84

e5. Leitlinien BVA/DOG: Leitlinie 15a/c, Primär chronisches Offenwinkelglaukom, Normaldruckglaukom und okuläre Hypertension. www.augeninfo.de/leit/index.htm

e6. Michelson G, Hornegger J, Wärntges S, Lausen B: The papilla as screening parameter for early diagnosis of glaucoma. Dtsch Arztebl Int 2008; 105(34-35): 583-9.

e7. Sycha T, Vass C, Findl 0, Bauer P, Groke I, Schmettere L, Eichler HG: Intervention for normal tension glaucoma. Cochrane Database Syst Rev 2003; Issue 1. Art.No. CD 002222

e8. Hedman K, Watson PG, Alm A: The effect of latanoprost on intraocular pressure during 2 years of treatment. Surv Ophthalmol 2002; 47 (Suppl 1): 65-76.

e9. Law SK, Kim E, Yu F, Caprioli J: Clinical cystoid macular edema after cataract surgery in glaucoma patients. J Glaucoma 2009 (epub ahead of print).

e10. Tomita G, Niwa Y, Shinohara H, Hayashi N, Yamamoto T, Kitazawa Y: Changes in optic nerve head blood flow and retrobular hemodynamics following calcium-channel blocker treatment of normal-tension glaucoma. Int Ophthalmol 1999; 23: 3-10.

e11. Gugleta K, Orgul S, Stumpfig D, Dubler B, Flammer J: Fludrocortisone in the treatment of systemic hypotension in primary open-angle glaucoma patients. Int Ophthalmol 1999; 23: 25-30.

e12. Law SK, Li T: Acupuncture for glaucoma. Cochrane Database Syst Rev 2007, Issue 4. Art.No. 006030. e13. Burr J, Azuara-Blanco A, Avenell A: Medical versus surgical interventions for open angle glaucoma. Cochrane Database Syst Rev 2004, Issue 2. Art.No. CD004399.

e14. Wilkins M, Indar A, Wormald R: Intra-operative Mitomycin C for glaucoma surgery. Cochrane Database Syst Rev 2005, Issue 4. Art.No. CD002897.

e15. Wormald R, Wilkins M, Bunce C: Postoperative 5-Fluorouracil for glaucoma surgery. Cochrane Database Syst Rev 2001, Issue 3. Art.No. 001132.

e16. Minckler D, Vedula SS, Li T, Mathew M, Ayyala R, Francis B: Aqueous shunts for glaucoma. Cochrane Database Syst Rev 2006, Issue 2. Art.No. 004918

e17. Krott R, Diestelhorst M, Zollweg M, Krieglstein GK: Dose response relationship of transscleral contact cyclophotocoagulation. Ophthalmologe 1997; 94: 273-6.

e18. Becker M, Funk J: Diode laser cyclophotocoagulation as the primary surgical intervention in glaucoma. Ophthalmologe 2001; 98: 1145-8.

e19. Rolim de Moura C, Paranhos A Jr, Wormald R: Laser trabeculoplasty for open-angle glaucoma. Cochrane Database Syst Rev 2007; Issue 4. Art.No.: CD 003919.

e20. Mcllraith I, Strasfeld M, Colev G, Hutnik CM: Selective laser trabeculoplasty as initial and adjunctive treatment for open-angle glaucoma. J Glaucoma 2006; 15: 124-30.

e21. Best UP, Domack H, Schmidt V: Langzeitergebnisse nach selektive Lasertrabekuloplastik - eine klinische Studie an 269 Augen. Klin Monatsbl Augenheilkd 2005; 222: 326-31.

e22. Lewis RA, von Wolff K, Tetz M, Korber N, Kearney JR, Shingleton B, Samuelson TW: Canaloplasty: circumferential viscodilation and tensioning of Schlemm's canal using a flexible microcatheter for the treatment of open-angle glaucoma in adults: interim clinical study analysis. J Cataract Refract Surg 2007; 33: 1217-26.

e23. Detry-Morel M, Pourjavan S, Detry MB: Comparative safety profile between „modern" trabeculectomy and non-penetrating deep sclerectomy. Bull Soc Belge Ophthalmol 2006; 300: 43-54.

e24. Gray TA, Orton LC, Henson D, Harper R, Waterman H: Interventions for improving adherence to ocular hypotensive therapy. Cochrane Database Syst Rev 2009, Issue 2, Art.No. CD 006132. 